\title{
A three-mode factor analysis of the concept of novelty'
}

ALAN L. BERNSTEIN and FRANK W. WICKER, ${ }^{2}$ Tufts University, Medford, Mass. 02155

Although psychologists have dealt with the concept of novelty in divergent ways, suggesting that the concept might be multidimensional, a factor analysis of Ss' ratings of 18 descriptive scales resulted in only one significant factor for each of three modes of data variation. Thirty college students were asked to rate five congruous and five incongruous animal slides on a series of 18 adjective scales. A Tucker three-mode factor analysis of the data was performed with adjectives, slides, and $S s$ as the variables. In general, the results favored a unidimensional concept of novelty and failed to indicate a systematic basis for individual differences.

Within the last two decades psychologists have become interested in the construct of novelty and its implications for both human and animal behavior. Alternative explanations (e.g., Glanzer, 1958; Berlyne, 1960; Dember, 1960; Fiske \& Maddi, 1961) have been proposed to explain the empirical data. Since these alternative explanations seem to deal with the data in divergent ways using different types of constructs (e.g., arousal, satiation, and expectancy), it can be questioned whether novelty is best conceptualized as a uni- or multidimensional variable. This question arises from a lack of clarity as to whether alternative theorists are using different terminology to describe essentially the same phenomenon or whether they are describing different aspects of a multidimensional phenomenon.

It is the purpose of the present study to test the dimensionality of the concept of novelty and to determine the importance of individual differences in Ss' judgments about this concept.

\section{MATERIALS}

Projection slides of five congruous (realistic) and five incongruous (novel or nonrealistic) animals were constructed (see Fig. 1). The slides were projected from an automatic slide projector onto a daylight screen. Eighteen 10-point adjective scales which seemed to possess both theoretical and descriptive appropriateness for defining the concept of novelty were used to rate each slide (see the left hand column of Table 1 ).

\section{PROCEDURE}

Booklets of 10 separate response sheets, each containing the 18 scales, were handed out to $\mathrm{Ss}$ who were seated at several long tables in a semidarkened room. Ss performed in groups of three to seven and all were read a standard set of instructions which asked them to rate each slide in terms of each of the adjective scales listed on a page, placing a check mark in the interval which they felt best described each of the stimuli.

The slides were shown one at a time in the same order for all Ss. A given slide remained exposed until all Ss had completed their rating of it.

The ratings for each adjective scale were scored from -4.5 to +4.5 and a three-mode factor analysis (Tucker, 1964) of the data was performed, using a slightly modified version of a program written by Walsh (1964). This analysis makes it possible to infer the number of factors of "novelty" involved in the adjective scale mode of data variation, the number of factors involved in the stimulus slide mode, and the factorial structure of the between-Ss variability. The method also produces a three-dimensional "core" matrix which indicates the relationship among the three types of factors obtained.

\section{SUBJECTS}

Thirty college students from an introductory psychology course at Tufts University served as Ss. All had served in a
Table 1

Factor Loadings for the Adjective Pairs

\begin{tabular}{lrr}
\hline Adjective Scales & \multicolumn{2}{c}{ Factor } \\
\hline & \multicolumn{1}{c}{$\mathrm{A}$} & \multicolumn{1}{c}{$\mathrm{B}$} \\
\hline phoney - authentic & -56.146 & -11.048 \\
simple - complex & 27.878 & -28.068 \\
real - unreal & 58.510 & 13.045 \\
congruous - incongruous & 60.094 & -1.856 \\
silly - not silly & -46.331 & -11.865 \\
expected - surprising & 39.638 & -1.897 \\
normal - abnormal & 62.183 & 2.305 \\
novel - ordinary & -58.669 & 6.610 \\
serious - funny & 31.854 & 9.616 \\
exciting - dull & -16.663 & 36.587 \\
familiar - strange & 61.565 & -5.687 \\
imaginary - existing & -58.843 & -6.163 \\
colorful - colorless & -8.338 & 45.556 \\
believable - make believe & 60.984 & 1.049 \\
typical - non typical & 60.817 & -511 \\
meaningless - meaningful & -19.632 & -32.016 \\
arousing - non arousing & -14.647 & 40.863 \\
usual - unusual & 60.803 & -2.561 \\
\hline
\end{tabular}

verbal learning experiment just prior to taking part in the present study.

\section{RESULTS AND DISCUSSION}

Table 1 gives the loadings on the first two factors for adjective pairs. Although a plot of successive latent roots seemed to indicate two distinct adjective factors accounting for $68.3 \%$ (Factor A) and $12.2 \%$ of the variance (Factor B), the mean rating on each adjective scale and its respective loading on Factor B were correlated .85. This indicates that Factor B was really a means factor which resulted from applying principal components procedures to a matrix of cross-products rather than to a matrix of correlations. Loadings on this factor reflect the ratings of the "average" stimulus. Factor A seemed to be a general congruity or familiarity factor on which most of the scales had substantial loadings.

Table 2 is a list of the factor loadings for the slides. The proportion of variance accounted for by the two factors was
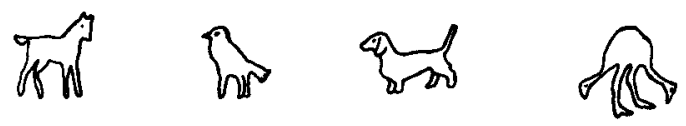

$$
1-C
$$

$2-N$

3-C

4-N
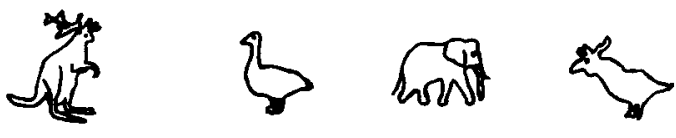

5-N

6.C

7-C

$.8-N$
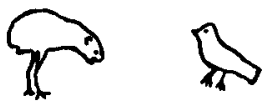

$9-\mathbf{N}$

$10-c$

Fig. 1. The congruous (c) and the incongruous (n) stimulus material used in the experiment. The numbers refer to the order of presentation. 
Table 2

Factor Loadings for the Slides

\begin{tabular}{crc}
\hline Slide Number & \multicolumn{3}{c}{ Factor } \\
\hline & \multicolumn{1}{c}{ A } & B \\
\hline 1 (c) & -42.715 & 42.724 \\
2 (n) & 62.185 & 31.766 \\
3 (c) & -40.480 & 37.511 \\
4 (n) & 75.830 & 20.066 \\
5 (n) & 76.101 & 22.861 \\
6 (c) & -55.697 & 32.407 \\
7 (c) & -57.045 & 26.368 \\
8 (n) & 79.649 & 22.056 \\
9 (n) & 75.997 & 23.008 \\
10 (c) & -62.421 & 34.184 \\
\hline
\end{tabular}

a congruous animal

$b$ incongruous animal

Table 3

Core Matrix for Subject Factor A

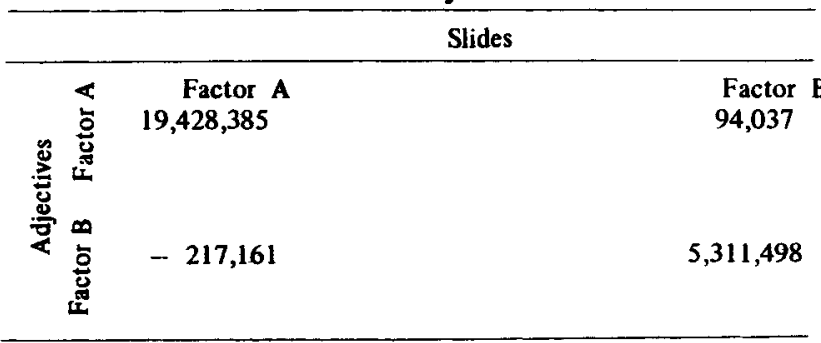

$66.5 \%$ and $14.7 \%$, respectively. The first factor could clearly be characterized as a congruity-incongruity dimension whereas the second factor again seemed to be a means factor. Thus, for stimuli and slides, novelty seems to be a unidimensional variable.

The results of the factor analysis also seemed to indicate that only one factor should be retained for Ss. The first factor accounted for $67 \%$ of the variance, while successive orthogonal axes each accounted for less than $5 \%$. Loadings on the first factor seemed to correspond to the mean judgments for an individual; hence, individual differences did not seem to reflect any large systematic deviation from the modal point of view.

The core matrix (Table 3 ) indicated that there was a very simple relationship between adjective and slide factors. The novelty factor for adjectives was highly related to the novelty factor for slides and the means factor for adjectives corresponded to the means factor for slides.

\section{REFERENCES}

BERLYNE, D. E. Conflict, arousal, and curiosity. New York: McGraw-Hill, 1960.

DEMBER, W. N. The psychology of perception. New York: Holt, Rinehart, \& Winston, 1960

FISKE, D. W., \& MADDI, S. R. A conceptual framework. In D. W. Fiske and S. R. Maddi (Eds.), Functions of varied experience. Homewood, Illinois: Dorsey, 1961. Pp. 11-56.

GLANZER, M. Curiosity, exploratory drive, and stimulus satiation. Psychological Bulletin, 1958, 55, 302-315.

TUCKER, L. R. The extension of factor analysis to three-dimensional matrices. In N. Frederiksen (Ed.), Contributions to mathematical psychology. New York: Holt, Rinehart, \& Winston, 1964.

WALSH, J. A. An IBM 709 program for factor analyzing three-mode matrices. Educational and Psychological Measurement, 1964, 24, 669-673.

NOTES

1. The authors wish to acknowledge both the Computation Center of the Massachusetts Institute of Technology where the data analysis was carried out on an IBM 7094 computer and the Tufts University Psychology Department which provided the necessary funding.

2. Now at Pennsylvania State University.

\section{(Continued from page 290)}

Group E and Group C. In examining the recall protocols it was noted that not one $S$ in Group $E$ included the clustered recall of the last critical pair among the first four items recalled.

There were six two-member categories defined by the random pairing used for Group E. Category recall was defined by the appearance of at least one member of the category during recall. The mean category recall for Group $E$ was 4.85 and for Group $C, 5.60$. The difference between groups was significant $[\mathrm{F}(1,38)=13.92, \mathrm{p}<.01]$.

Group $C$ surpassed Group $E$ in the number of words recalled. The mean recall for Group $C$ was 11.55 , compared to a mean recall of 10.40 for Group $E$. The difference between these means did not reach an acceptable level of statistical significance $[F(1,38)=3.31]$. The clustering advantage demonstrated in Group $\mathrm{E}$ was not accompanied by a similar advantage in correct recall.

There were very few outside-list intrusions or repetitions of list words during recall. The combined means of such responses per $\mathrm{S}$ were .35 for Group $\mathrm{E}$ and .45 for Group $\mathrm{C}$.

The present results demonstrated that input contiguity provided a sufficient basis for clustering during free recall. Similar results have been obtained by Greenhouse (1967), who found that temporal grouping of three and four unrelated words led to clustering of these words during recall. However, Greenhouse also reported advantages in number of words recalled following temporal grouping during presentation, a result which did not obtain in the present experiment.

\section{REFERENCES}

ASCH, S. E., \& EBENHOLTZ, S. M. The process of free recall: Evidence for non-associative factors in acquisition and retention. Journal of Psychology, 1962, 54, 3-31.

BOUSFIELD, W. A., COHEN, B. H., \& WHITMARSH, G. A. Associative clustering in the recall of words of different taxonomic frequencies of occurrence. Psychological Reports, 1958, 4, 39-44.

DEESE, J. Influence of inter-item associative strength upon immediate free recall. Psychological Reports, 1959, 5, 305-312.

DEESE, J., \& KAUFMAN, R. A. Serial effects in recall of unorganized and sequentially organized verbal material. Journal of Experimental Psychology, 1957, 54, 180-187.

GREENHOUSE, P. Free recall of categorized and unrelated words under serial or grouped presentation. Psychonomic Science, 1967, 8, 447448.

JAHNKE, J. C. Primacy and recency effects in serial-position curves of immediate recall. Journal of Experimental Psychology, 1965, 70, 130-132.

JENKINS, J. J., \& RUSSELL, W. A. Associative clustering during recall. Journal of Abnormal \& Social Psychology, 1952, 47, 818-821.

KEPPEL, G. Association by contiguity: Role of response availability. Journal of Experimental Psychology, 1966, 71, 624-628.

SPEAR, N. E., EKSTRAND, B. R., \& UNDERWOOD, B. J. Association by contiguity. Journal of Experimental Psychology, 1964, 67, 151-161.

\section{NOTES}

1. This research was supported by Grant GB8605 from the National Science Foundation.

2. Wallace, W. P. The influence of test trials on the development of subjective organization in free recall. Submitted for publication. 